\title{
Predictive Factors for Acute Proximal Junctional Failure after Adult Deformity Surgery with Upper Instrumented Vertebrae in the Thoracolumbar Spine*
}

\author{
Prokopis Annis ${ }^{1}$ Brandon D. Lawrence ${ }^{1}$ William R. Spiker ${ }^{1}$ Yue Zhang ${ }^{2}$ Wei Chen ${ }^{2}$ \\ Michael D. Daubs ${ }^{3}$ Darrel S. Brodke ${ }^{1}$
}

${ }^{1}$ Department of Orthopaedics, University of Utah, Utah, United States

${ }^{2}$ Division of Epidemiology, Department of Internal Medicine, University of Utah, Utah, United States

${ }^{3}$ Department of Orthopaedics, University of Nevada, Nevada, United States

Address for correspondence Prokopis Annis, MD, Department of Orthopaedics, University of Utah, 590 Wakara Way, Salt Lake City, UT 84108, United States (e-mail: prokopis.annis@hsc.utah.edu).

Evid Based Spine Care J 2014;5:160-162.

\begin{abstract}
Study Type Retrospective cohort study.

Introduction Acute proximal junctional failure (APJF) was recently defined by the International Spine Study Group as: postoperative fracture of the upper instrumented vertebrae (UIV) or UIV + 1; UIV implant failure; proximal junctional kyphosis (PJK) increase $>15$ degrees; or need for proximal extension of the fusion within 6 months of surgery. ${ }^{1}$ The incidence and revision rates of APJF have been reported to be higher when the UIV is located in the lower thoracolumbar (TL) spine mostly because of high incidence of UIV or UIV +1 fractures. $^{2}$ Sagittal deformity overcorrection has been considered as a potential risk factor. ${ }^{3,4}$

Objective The purpose of this study is to assess independent predictive factors and timing for revisions of APJF in adult deformity patients with UIV in the TL (T9-L2) spine. Methods Retrospective review of 135 consecutive patients with minimum 2-year follow-up, treated at a single institution for adult spinal deformity, all with UIV in the TL spine (T9-L2). Fusions were divided into three cohorts based on the UIV location (T9-T10 vs. T11-T12 vs. L1-L2). Demographic data were reviewed and radiographic parameters were measured preoperatively, immediately postoperatively, at 6 months and at the final follow-up. Incidence and failure modes of APJF, as well as timing for APJF revision are reported. Risk factors for APJF were assessed with univariate and multivariate regression analysis models.

Results A total of 135 consecutive patients were reviewed, with mean follow-up 42 months (24-126). Mean age was 66 years (24-86). There were no differences in the preoperative radiographic parameters between patients in any of the three cohorts with APJF. The incidence of APJF was 38.5\%, with a trend toward higher APJF in the T9-T10 group $(p=0.07)$ ( - Table 1 ).
\end{abstract}

Consistent with EBSJ's commitment to fostering quality research, we are pleased to feature some of the most highly rated abstracts from the 12th Annual AOSpine North America Fellows Forum in Banff, Canada. Enhancing the quality of evidence in spine care means acknowledging and supporting the efforts of young researchers within our AOSpine North America network. We look forward to seeing more from these promising researchers in the future.

received

May 15, 2014

accepted

June 3, 2014 (c) 2014 Georg Thieme Verlag KG

Stuttgart · New York
DOI http://dx.doi.org/ 10.1055/s-0034-1386755. ISSN 1663-7976. 
When UIV was at $\mathrm{T} 10$, the incidence of APJF was $57.1 \%$, significantly higher than the adjacent vertebrae, $\mathrm{T} 9$ and $\mathrm{T} 11$ ( $p=0.03$ and $p=0.01$, respectively). The overall revision rate for APJF was $17 \%$, most often for UIV fracture, while PJK $>15$ degrees alone had the highest 2 and 5 years survival (100\%) ( $\mathbf{- F i g . ~ 1 ) . ~ U n i v a r i a t e ~ a n a l y s i s ~ r e v e a l e d ~ p r e o p e r a t i v e ~ s a g i t t a l ~ v e r t i c a l ~}$ axis $>5 \mathrm{~cm}$, postoperative PJA $>5$ degrees and thoracic kyphosis $>30$ degrees, and instrumentation to the pelvis as risk factors for APJF (-Table 2). Multivariate regression analysis confirmed postoperative PJA $>5$ degrees, and greater correction of lumbar lordosis (LL) as independent risk factors for APJF (- Table 3).

Conclusion The incidence of APJF in adult deformity patients is high if the UIV is in the lower thoracic or lumbar spine, with a trend toward higher rates when the UIV is at T10. Fracture at the UIV lead to the highest revision rate, while PJK $>15$ degrees without fracture or hardware failure had the longest revision-free survival. Postoperative PJA $>5$ degrees and greater correction of LL are independent risk factors for APJF.

Table 1 Incidence and revision rates of APJFs in the three groups

\begin{tabular}{|l|l|l|l|l|}
\hline & All (135) & T9-T10 (52) & T11-T12 (45) & L1-L2 (33) \\
\hline APJFs & $52(39 \%)$ & $25(48 \%)$ & $14(31 \%)$ & $13(39 \%)$ \\
\hline UIV, UIV + 1 fracture & $32(62 \%)$ & $19(76 \%)$ & $8(57 \%)$ & $5(38 \%)$ \\
\hline PJK $>15$ degrees & $11(21 \%)$ & $3(12 \%)$ & $3(21 \%)$ & $5(39 \%)$ \\
\hline UIV implant failure & $8(15 \%)$ & $2(8 \%)$ & $3(21 \%)$ & 0 \\
\hline$<6$ mo revision & $1(2 \%)$ & $1(4 \%)$ & $0(0 \%)$ & 0 \\
\hline Revision APJF & $23(44 \%)$ & $10(40 \%)$ & $6(43 \%)$ & $7(54 \%)$ \\
\hline UIV, UIV + 1 fracture & $16(70 \%)$ & $8(80 \%)$ & $3(50 \%)$ & $5(71 \%)$ \\
\hline PJK $>15$ degrees & $0(0 \%)$ & $0(0 \%)$ & $0(0 \%)$ & $0(0 \%)$ \\
\hline UIV implant failure & $6(26 \%)$ & $1(10 \%)$ & $3(50 \%)$ & $2(0 \%)$ \\
\hline$<6$ mo revision & $1(4 \%)$ & $1(10 \%)$ & $6 / 45(13 \%)$ & $0(0 \%)$ \\
\hline Overall revision APJF & $23 / 135(17 \%)$ & $10 / 52(19 \%)$ & $7 / 33(21 \%)$ \\
\hline
\end{tabular}

Kaplan Meier 2 years
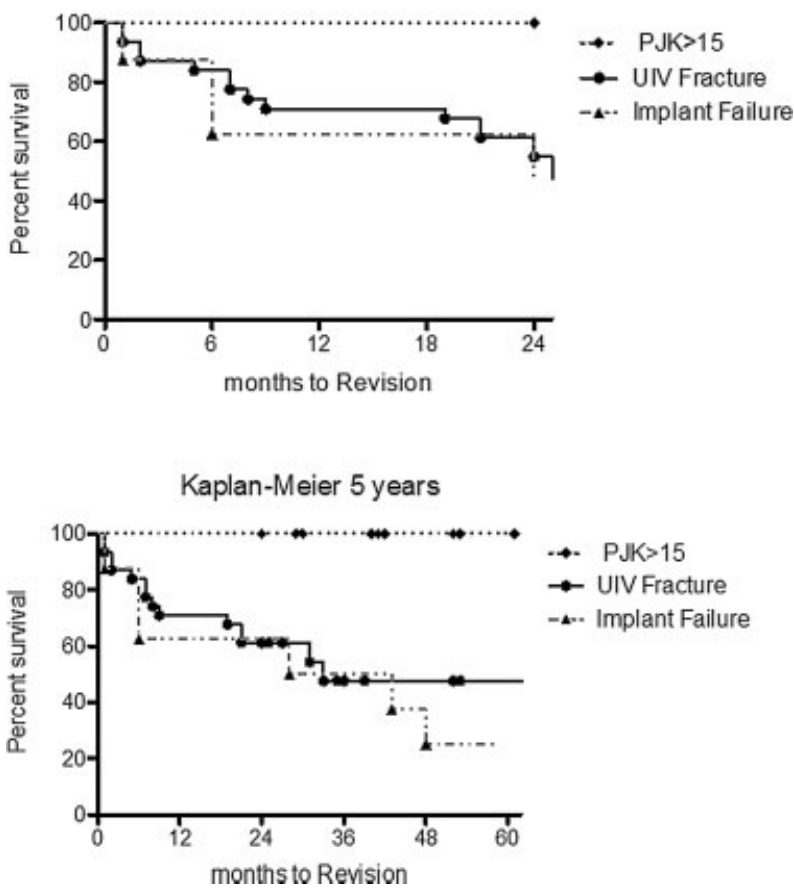

Fig. 1 Kaplan-Meier curve at 2 and 5 years.
Table 2 Univariate logistic on APJF with age adjustment

\begin{tabular}{|l|l|l|}
\hline Variable names & OR $(95 \% \mathrm{Cl})$ & $\boldsymbol{p}$ value \\
\hline Pre-SVA $>5$ & $2.46(1.19,5.1)$ & 0.015 \\
\hline Post-PJA $>5$ & $36.63(4.79,280)$ & 0.001 \\
\hline Imm-post ThK $>30$ & $2.5(1.11,5.63)$ & 0.027 \\
\hline Instrumentation to pelvis & $2.19(1.07,4.48)$ & 0.032 \\
\hline LL change $>30$ & $4.81(1.9,12.17)$ & 0.001 \\
\hline
\end{tabular}

Abbreviations: $\mathrm{Cl}$, confidence interval; Imm-post, immediately postoperative standing X-ray; LL, lumbar lordosis; OR, odds ratio; PJA, proximal junctional angle; SVA, sagittal vertical axis; ThK, thoracic kyphosis.

Table 3 Multivariate logistic regression on APJF

\begin{tabular}{|l|l|l|}
\hline Variable names & OR $(95 \% \mathrm{Cl})$ & $p$ value \\
\hline LL change $>30$ degrees & $6.94(1.67,28.75)$ & 0.008 \\
\hline Post-PJA $>5$ degrees & $27.77(3.18,242.47)$ & 0.002 \\
\hline
\end{tabular}

Abbreviations: $\mathrm{Cl}$, confidence interval; Post, immediately postoperative standing X-ray; LL, lumbar lordosis; OR, odds ratio; PJA, proximal junctional angle. 
Note

Approval was obtained for this project by the University of Utah Institutional Review Board.

\section{Disclosures}

Prokopis Annis, none

Brandon D. Lawrence, Consultant: Amedica

William R. Spiker, Consultant: Amedica

Yue Zhang, none

Wei Chen, none

Michael D. Daubs, Consultant: DePuy Synthes; Royalties:

DePuy Synthes

Darrel S. Brodke, Consultant: Amedica, DePuy Synthes; Royalties: Amedica, DePuy Synthes, Medtronic; Stock/ stock options: Amedica

\section{References}

1 Hostin R, McCarthy I, O’Brien M, et al; International Spine Study Group. Incidence, mode, and location of acute proximal junctional failures following surgical treatment for adult spinal deformity. Spine (Phila Pa 1976) 2013;38(12):1008-1015

2 Kim YJ, Bridwell KH, Lenke LG, Rhim S, Kim YW. Is the T9, T11, or L1 the more reliable proximal level after adult lumbar or lumbosacral instrumented fusion to L5 or S1? Spine (Phila Pa 1976) 2007: 32(24):2653-2661

3 Yagi M, Akilah KB, Boachie-Adjei O. Incidence, risk factors and classification of proximal junctional kyphosis: surgical outcomes review of adult idiopathic scoliosis. Spine (Phila Pa 1976) 2011; 36(1):E60-E68

4 Yagi $\mathrm{M}$, King $\mathrm{AB}$, Boachie-Adjei O. Incidence, risk factors, and natural course of proximal junctional kyphosis: surgical outcomes review of adult idiopathic scoliosis. Minimum 5 years of follow-up. Spine (Phila Pa 1976) 2012;37(17):1479-1489 